\title{
MAKNA DAN NILAI PAPPASENG DALAM LONTARA'LATOA KAJAO LALIDDONG DENGAN ARUMMPONE: ANALISIS HERMENEUTIKA
}

\author{
Besse Tenri Rawe, Muhammad Darwis, Dafirah \\ Program Magister Ilmu Linguistik, \\ Fakultas Ilmu Budaya, Universitas Hasanuddin \\ bassetenrirawe@gmail.com
}

\begin{abstract}
This study aims to explain the form, meaning, and value of pappaseng in Lontara 'Latoa: Kajao Laliddong with Arummpone by using Paul Ricouer's hermeneutic approach. This research is a qualitative research. The research data are in the form of Lontara 'Latoa: Kajao Laliddong and Arummpone texts. Data collection method used by the author is a library method by gathering information relevant to the topic or problem to be or is being studied. That information can be obtained from scientific books, research reports, scientific essays, theses and dissertations, regulations, provisions, yearbooks, encyclopedias, and written sources both printed and electronic. Data were analyzed using Paul Ricouer's hermeneutic analysis. The results of this study indicate the form of pappaseng in the form of dialogue discourse consisting of expressions and proverbs. The meaning of Pappaseng that was found consisted of three, namely the description of the characteristics of a good leader, a sign of the triumph of the state, and a characteristic of the destruction of the state. These three meanings gave birth to Bugis values including: honesty (alêmpureng), intellectual value (amaccangêng), firmness value (agêttêngêng), and family and love values (assiajingêng).

Keywords: pappaseng - lontara '- Latoa - Kajao Laliddong - Arummpone
\end{abstract}

\section{PENDAHULUAN}

Arus modernisasi membawa perubahan yang banyak dalam kehidupan masyarakat. Perubahan tersebut berdampak negatif yang menyebabkan terjadinya penyakit krisis moral dan akhlak. Pelan tapi pasti hampir semua elemen bangsa ikut merasakannya. Misalnya: ricuhnya pemilukada, korupsi politisi merajalela, hingga aksi tebar janji-janji politik menjelang pemilukada. Diperparah dengan merebaknya gaya hidup pragmatik, melembaganya aksi kekerasan, juga ikut melemahkan karakter anak bangsa sehingga nilai-nilai luhur dan kearifan sikap hidup menjadi kian terkikis.

Ada pepatah yang mengatakan jika hati sudah baik, maka baik pulalah seluruh anggota badan. Hati diibaratkan sebagai pemimpin dalam sebuah negara, sedangkan anggota badan sebagai masyarakatnya. Hal pertama yang harus diperbaiki jika ingin melihat sebuah negara sukses dan maju adalah karakter dan moral pemimpinnya. Karakter dan moral pemimpin yang baik akan membawa karakter dan moral masyarakat yang baik pula, karena pemimpin adalah cerminan dan teladan bagi masyarakatnya.

Banyak cara pandang, nasehat dan petuah yang bisa dijadikan acuan bagi pemimpin dalam mengelolah negaranya. Tidak perlu jauh-jauh mencarinya apalagi mengambilnya dari negara lain. Bangsa Indonesia sangat kaya dengan warisan budaya leluhur.

Salah satu jenis warisan budaya Bugis yang sarat nilai luhur adalah karya sastranya. Selain tingkat populasi masyarakatnya yang tinggi, masyarakat Bugis juga memiliki tradisi kesusastraan yang kaya, baik lisan maupun tulisan. Berbagai karya sastra tulis yang berkembang seiring dengan tradisi lisan, hingga kini masih tetap dibaca dan disalin ulang. Perpaduan antara tradisi lisan dan sastra tulis itu kemudian menghasilkan salah satu epos sastra terbesar di dunia yaitu La Galigo yang lebih panjang dari Mahabharata (Pelras, 2006: 4).

Salah satu jenis lontara' selain $L a$ Galigo yang cukup dikenal dan bisa dijadikan acuan dan pedoman masyarakat Bugis dalam kehidupannya yaitu La Toa. Berbeda dari La Galigo yang berisi 


\section{6 | JURNAL ILMU BUDAY}

Volume 8, Nomor 1, Juni 2020 himpunan mitologi Bugis yang kebenarannya diragukan karena coraknya yang tidak tersentuh akal. La Toa merupakan salah satu lontara' yang logis berisikan himpunan amanat para orang bijaksana dan raja zaman dahulu (Mattulada, 1995: 10).

Latoa berisi banyak nilai-nilai luhur kebudayaan dalam bentuk pesan-pesan (pappseng) raja dan orang-orang bijak di zamannya yang bisa diterapkan pula dalam kehidupan sekarang. Nilai-nilai kearifan dan kebajikan masa lalu yang bisa mengokohkan karakter dan kepribadian generasi sekarang agar tidak tertimbun dan tergeser dengan hiruk-pikuk modernisasi saat ini. Nilai-nilai tersebut haruslah tetap dijaga dan dilestarikan. Oleh karena itu, perlu dikaji lebih mendalam agar lebih mudah dipahami dan diterapkan dalam kehidupan masyarakat.

Salah satu bagian dari lontara' Latoa yang bisa dikatakan sebagai induk atau patokan dasar dari amanat para orang bijaksana dan raja zaman dahulu yang terkandung di dalamnya adalah dialog atau perkacapan antara Kajao Laliddong dengan Arumpone. Bagian ini menjadi pembuka dalam naskah lontara' Latoa tersebut. Adapun konsep dasar yang diusung adalah sebuah sistem norma yang berlaku pada masyarakat Bugis yang disebut pangngadêrêng. Konsep ini kemudian terjabarkan dan diperkuat dengan petuahpetuah atau amanat para orang bijaksana dan raja zaman dahulu setelahnya.

\section{METODE PENELITIAN Jenis dan Metode Penelitian}

\section{Penelitian ini menggunakan pendekatan kualitatif dengan metode hermeneutik Paul Ricouer. Pengumpulan data melalui studi pustaka dengan penelusuran naskah lontaraq pappaseng dan studi dokumentasi. Penelitian ini menggunakan pendekatan penelitian kualitatif dengan metode fenomenologi karena fokus dan permasalahan kajian mengupas berkaitan dengan makna yang terkandung dibalik teks dalam naskah lontara' Latoa: Kajao Laliddong dengan Arummpone, dan meneropong makna dibalik sikap dan perilaku orang Bugis.}

Sumber data yang digunakan adalah naskah lontara' yang aslinya berbahasa Bugis, namun dalam penelitian ini naskah lontara' yang digunakan adalah naskah yang telah dikumpulkan oleh para filolog dan para budayawan Bugis (telah ditransliterasikan ke dalam bahasa Indonesia) yang berisi berbagai pesan/nasihat dari para leluhur manusia Bugis. Di antara buku utama yang digunakan adalah buku yang ditulis oleh Mattulada Latoa Suatu Lukisan Analitis Terhadap Antroplogi Politik Orang Bugis (1995). Data pendukung lainnya diperoleh dari buku-buku, tesis, disertasi, buletin dan jurnal-jurnal ilmiah, serta berbagai dokumen yang relevan dan membahas mengenai nilainilai kearifan lokal Manusia Bugis.

Begitu luas dan dalam jika mengkaji 'tentang lontara' ini, namun dalam kajian ini, hanya dibatasi pada kajian bentuk, makna dan nilai pappaseng yang terdapat di dalamnya. Jika dicermati dan dikaji secara mendalam, lontara' Latoa pappaseng ternyata memuat banyak hal yang berkaitan dengan nilai-nilai luhur budaya. Nilai-nilai kebudayaan yang dimaksud, sangat penting untuk dikaji dan diangkat ke permukaan, sebab nilai-nilai luhur yang dimuat di dalamnya masih sangat relevan untuk menghadapi kehidupan masa kini, begitu juga pada masa yang akan datang dalam gempuran modernisasi saat ini.

Menurut Pelras (2006: 244)

Pappaseng adalah salah satu jenis prosa lisan menggunakan bahasa kuno berisi nasihat dan tata perilaku menurut leluhur.

Pengungkapan Pappaseng dapat dilakukan dalam bermacam-macam bentuk, yaitu 1) Pappaseng dalam bentuk elong, elong berarti puisi atau nyanyian agar Pappaseng disampaikan dapat berkesan di hati dan diterapkan dalam kehidupan seharihari; 2) Pappaseng dalam bentuk warekkada, warekkada berarti ungkapan atau peribahasa dalam bentuk perkataan atau kelompok kata yang khusus untuk menyatakan suatu maksud dalam arti kiasan; 3) Pappaseng dalam bentuk percakapan, baik monolog maupun dialog, monolog adalah yang diucapkan seorang diri sedangkan dialog adalah percakapan dua orag atau lebih (Iskandar, 2016).

Mattaliti (1986: 6) mengemukakan bahwa pappaseng berisikan petunjukpetunjuk dan nasihat dari nenek moyang 


\section{7 | JURNAL ILMU BUDAY}

Volume 8, Nomor 1, Juni 2020 orang Bugis pada zaman dahulu untuk anak cucunya agar menjalani hidup dengan baik. Sedangkan menurut Punagi (1983: 3) menyatakan bahwa pappaseng adalah wasiat orang tua kepada anak cucunya (orang banyak) yang harsu selalu diingat sebagai amanah yang perlu dipatuhi dan dilaksanakan.

Adapun fungsi pappaseng (Iskandar, 2006) antara lain: sebagai sarana dan media kontrol sosial; sebagai sarana pelindung norma kemasyarakatan; sebagai sarana pendidikan; dan sebagai pedoman atau acuan dalam kehidupan.

\section{HASIL DAN PEMBAHASAN}

Pada dasarnya naskah lontara' Latoa dituliskan dalam bentuk percakapan / dialog berisi 9 bagian ucapan/petuah rajaraja dan orang Bugis pada zaman itu, salah satunya tanya jawab/dialog antara Kajao Laliddong dengan Arumpone (Raja Bone) pada masa itu yaitu La Tenri Rawe Bongkangnge. Berdasarkan naskahnya percakapan mereka terdiri dari 31 alenia.

Adapaun naskah lontara' Latoa yang digunakan di sini adalah yang telah diterbitkan Matthes dalam B.CHr. jilid II halaman 1 s/d 180, Amsterdam, 1872 (Mattulada, 1995: 84).

Setelah membaca dan mencermati dengan saksama naskah dan terjemahan Lontara' Latoa: Kajao Laliddong dengan Arumpone di atas, maka dapat dijabarkan bahwa pappaseng dalam naskah tersebut diungkapkan dalam dua bentuk yaitu dalam bentuk dialog/percakapan dan bentuk warekkada (ungkapan / peribahasa).

\section{Makna Pappaseng dalam Lontara' Latoa:} Kajao Laliddong dengan Arumpone

Makna yang penulis temukan dalam lontara' Latoa: Kajao Laliddong dengan Arumpone yang terdiri dari alenia 31 ini terdiri atas 3, yaitu: menjelaskan mengenai 1) ciri pemimpin yang baik; 2) tanda-tanda kehancuran negara; dan 3) tanda-tanda kejayaan negara.

\section{Ciri pemimpin yang baik}

Pertama, seorang pemimpin adalah pemersatu rakyatnya. Dengan kata lain, selalu menjaga persatuan dan kesatuan, tidak membiarkan rakyatnya tercerai-berai. Selain itu, menggunakan harta sebaikbaiknya dengan tidak berlebihan dan menggunakannya sesuai kebutuhan. Hal ini jelas tergambar pada kutipan lontara' Latoa berikut:

1) Makkêdai Kajao Laliddong, aga sio, Arumpone, muasêng, tettaroi nrêbba alêbbirêmmu, patokkopulanai alêbbirêng mubakurie, aja natattêrê - têrê tau têmbe'mu, aja napada wênno pangngampo waramparang mubakurie

5) Makkêdai Kajao Laliddong, ia inanna waramparangnge Arumpone, têttaroengngi natattêrê - têrê tau têmbe'na,....

Kedua, selalu meluangkan waktu yang banyak (bahkan harus tidak tidur siang dan malam) untuk memikirkan dan merenungkan hal-hal apa saja yang dapat memakmurkan atau menyejahterahkan negaranya yang tentunya akan berimbas baik kepada rakyat yang dipimpinnya Berikut kutipannya:

5) Makkêdai Kajao Laliddong, ia inanna waramparangnge Arumpone,.... têmmatinropi matanna arungnge ri êsso ri wênnie, nawa - nawai adecengênna tanana,;....

Ketiga, selalu mempertimbangkan baik-buruk, sebab-akibat dari setiap kebijakan yang akan diambil sebelum diputuskan dan diterapkan atau dilaksanakannya. Berikut kutipan yang menunjukkan hal ini:

5) Makkêdai Kajao Laliddong, ia inanna waramparangnge Arumpone,...... natangngai olona munrinna gau'e, napogau'i; maduanna, maccapi ppinru' ada arung mangkau'e.....

Keempat, pandai dan cakap dalam bertutur kata / mampu menerima dan melayani keluhan Jadi, salah satu ciri pemimpin yang baik adalah seorang yang teguh dan konsisten menjalan sistem norma yang berlaku dalam masyarakatnya. Selain itu mengetahui dengan baik segala aturan yang berlaku sehingga dapat memutuskan dengan tepat segala perkara demi kestabilan 


\section{8 | JURNAL ILMU BUDAY}

Volume 8, Nomor 1, Juni 2020

dan ketertiban dalam negaranya. Kutipannya sebagai berikut:

5) Makkêdai Kajao Laliddong, ia inanna waramparangnge Arumpone......, maccapi ppinru' ada arung mangkau'e; matêllunna, maccapi dduppai ada arung mangkau'e; maêppa'na, têngngaluppange surona ppoada ada tongêng

7) Makkêdai Kajao Laliddong, ianaritu Arumpone, macca ppinru' ada tau têssalae ri pangngadêrrêngnge

1) Makkêdai Kajao Laliddong, ianaritu Arumpone, riaseng macca dduppai ada, tau têssalae ri rapannge

Kelima, selalu berkata benar dan jujur dalam segala tindakannya Jadi, seorang pemimpin harus selalu berkata benar, benar dalam kaitannya dengan bicara berarti adil sehingga hak dan kewajiban rakyatnya dapat terpenuhi degan baik. Berikut kutipannya:

11) Makkêdai Kajao Laliddong, ianaritu Arumpone, riaseng tau tengngalupang surona ri ada tongêngnge, tau têttatakkalupae ri bicarae

Anjuran berlaku jujur juga dijelaskan pada Lontara' Latoa alenia 12 - 17. Kajao Laliddong menjelaskan pula saksi atau pembuktian dari kejujuran itu dalam bentuk tindakan dengan tidak mengambil hak orang lain Hal ini jelas dalam kutipan percakapan berikut:

12) Makkêdai Arumpone, apa appongênna accae, Kajao? (Berkata Arumpone, apa sumbernya kepandaian itu, wahai Kajao?)

13) Makkêdai Kajao Laliddong, lempu'e Arumpone

14) Makkêdai Arumpone, aga sabbinna lêmpue, Kajao

15) Makkêdai Kajao Laliddong, obbi'e Arumpone (Berkata Kajao Laliddongng, obbi'e (=seruan) itu, hai Arumpone)

16)

akkêdai Arumpone, agana ri obbirêng, Kajao? Makkêdai Kajao Laliddong, iana ri obbirêng, Arumpone, makkêdae aja muala
E-ISSN: 2621-5101 P-ISSN:2354-7294

tanê - ttanêng tania tanê
ttanêngmu,
waramparang

waramparammu, nataniato mana'mu, aja' to mupassu tedong tania tedommu, ênrêngnge annyarang tania annyarammu, aja to muala aju ripasanre' na tania iko pasanre'i, aja to muala aju riwêtta walia natani iko mpêttawaliwi

Keenam, seorang pemimpin harus cerdas dan cendekia. Kecendekiawan dikaitkan erat dengan kejujuran.. Kedua sifat ini yaitu jujur dan cakap mengacu pada tuturan dan tingkah laku. Keduanya saling terkait satu sama lain dan tidak bisa dipisahkan.

Berikut kutipan lontara' Latoa tentang kecendekiawan (acca) serta keterkaitannya dengan kejujuran (lempu):

17) Makkêdai Arumpone, aga sabbinna accae, Kajao?

18) Makkêdai Kajao Laliddong, gau'e sabbinna accae, arumpone

19) Makkêdai Arumpone, agana ri pogau', Kajao?

20) Makkêdai Kajao Laliddong, iana ri pogau, Arumpone, têmmangkalingai, ada maja ada madeceng

Ketujuh, seorang pemimpin harus teguh dan konsisten. Berikut kutipan lontara' Latoa tentang hal ini:

6) Makkêdai Kajao Laliddong, ianaritu Arumpone, macca ppinru' ada tau têssalae ri pangngadêrrêngnge

2) Tanda kehancuran negara

Berdasarkan isi Lontara' Latoa, Kajao Laliddong juga menyampaikan pesan mengenai tanda - tanda kehancuran sebuah negara. Pertama, pemimpin ceroboh dan khianat (tidak amanah) melaksanakan kewajibannyaBerikut kutipannya:

23) Makkêdai Kajao Laliddong, iana tanra cinna matena tana marajae, Arumpone, linga-lingae,......

Kedua, pemimpin tidak mau menerima pendapat, kritikan, dan nasihat dari mana pun. Pemimpin merasa diri paling benar sehingga tidak mau menerima 


\section{9 | JURNAL ILMU BUDAY}

Volume 8, Nomor 1, Juni 2020

pendapat apalagi kritik dari siapa pun, segala keputusan dan kebijakan diputuskannya sendiri tanpa pertimbangan dan masukan dari siapa pun. Berikut kutipannya:

12) Makkêdai Arumpone, aga tanra cinna matena tana marajae, Kajao?

13) Makkêdai Kajao Laliddong, iana tanra cinna matena tana marajae, Arumpone, linga-lingae, maduanna, nakko teai ri pakaingê arungnge, ......

Ketiga, tidak ada peranan dan sumbangsih dari orang-orang cerdik/pandai di dalam negara Jadi, sebaiknya orang-orang cerdik / pandai diberdayakan dan diberi kesempatan untuk mengaplikasikan ilmunya untuk kemaslahatan rakyat.

13) Makkêdai Kajao Laliddong, iana tanra cinna matena tana marajae, Arumpone, .................. de'e tomacca ri wanuae,

Keempat, hakim dengan mudahnya disuap / disogok (naenrekiwi waramparang = dinaiki harta/ disuap atau disogok, tomabbicarae $=$ pemimpin peradilan $/$ hakim) sehingga tidak kepastian hukum yang menyebabkan kekacauan dalam negara. Jadi sebaiknya dipilih seorang hakim yang jujur dan adil sehingga pelanggar hukum dapat memperoleh hukuman yang setimpal dengan perbuatannnya sehingga memicu efek jera yang berdampak pada kestabilan dalam masyarakat. Berikut kutipannya:

12) Makkêdai Kajao Laliddong, iana tanra cinna matena tana marajae, Arumpone,

maêppana, nakko naenrekiwi waramparang

tomabbicarae

Kelima, pemimpin membiarkan kejahatan dan kemaksiatan dalam negara. Dalam hal ini pemimpin tidak memberi tindakan tegas kepada para kriminal sehingga tindakan kriminal semakin meraja lela. Hal ini tercermin pada kutipan berikut ini:

12) Makkêdai Kajao Laliddong, iana tanra cinna matena tana marajae, Arumpone, wêddo
E-ISSN: 2621-5101 P-ISSN:2354-7294

pada gau'e ri lalêmpanua, ........................

27) Makkêdai Kajao Laliddong, naia tulae pattaungêng Arumpone, ............ matêllunna nakko sisalasalaini taue ri lalêmpanua,......

Keenam, pemimpin seperti kehilangan kasih sayang kepada rakyat atau abdinya / pemimpin tidak menyayangi rakyatnya.. Berikut kutipannya:

12) Makkêdai Kajao Laliddong, iana tanra cinna matena tana marajae, Arumpone,

maênnênna, tênnamaseiwi atanna Arummangkau'e

\section{3) Tanda kejayaan negara}

Pertama, pemimpinnya jujur (malêmpu) dan cendekia (macca). Jujur dan acca itu mencakup jujur dalam lisan dan perbuatan. Ketika kedua karakter ini dimiliki oleh seorang pemimpin maka kejayaan dan kemakmuran akan akan lebih mudah dicapai. Berikut kutipan lontara' Latoa Kajao Laliddong dengan Arumpone tentang hal ini:

24) Makkêdai Arumpone, aga tanranna namaraja tanae, Kajao?

25) Makkêdai Kajao Laliddong, dua tanranna namaraja tanae, Arumpone. Seuani, malêmmpu'I na macca arummangkau'e, maduanna, tessisala-salae rilalempanua

29) Makkêdai Kajao Laliddong, têllu tanranna nasawe ase, Arumpone. Seuani nakko malêmmpu'i Arummangkau'e,.....

Kedua, Tidak ada persengkataan (perselisihan, perkelahian, pembunuhan, dan sebagainya) yang memicu ketentraman dan kedamaian dalam negara. Berikut kutipannya:

24) Makkêdai Arumpone, aga tanranna namaraja tanae, Kajao?

25) Makkêdai Kajao Laliddong, dua tanranna namaraja tanae, 


\section{0 | JURNAL ILMU BUDAY}

Volume 8, Nomor 1, Juni 2020
Arumpone.

..............maduanna, tessisala-
salae rilalempanua 29)
Makkêdai Kajao Laliddong,
têllu tanranna nasawe ase,
Arumpone,.......... matêllunna
mattau seuapi taue ri
lalêmpanua

Ketiga, pemimpin mengayomi dan mengasihi rakyatnya. Hal ini tercermin dalam kutipan berikut:

30) Makkêdatopi Kajao Laliddong, iaritu adê'e, Arumpone, ppeassêriwi arajanna Arummangkau'e.......... nasanresi to madodonnge, naia bicarae, iana passaranngi assilangênna to mangkaga'e, .....

Keempat, bersatupadunya segenap elemen masyarakat dalam negara tersebut. Hal ini dilakukan demi terwujudnya cita-cita menuju ketertiban, keadilan, kesejahteraan dan kemakmuran rakyatnya. hal ini tercermin dalam kutipan di bawah Ini:

29) Makkêdai Kajao Laliddong, têllu tanranna nasawe ase, Arumpone......., mattau seuapi taue ri lalêmpanua

Kelima, ditegakkannya sistem norma yang berlaku di masyarakat oleh pemimpin dan pejabat hukum, dan segenap rakyat sehingga terwujud sistem pemerintahan yang baik. Hal ini diwujudkan dengan tertuang dalam kutipan lontara' berikut:

30) Makkêdatopi Kajao Laliddong, iaritu adê'e, Arumpone, ppeassêriwi arajanna Arummangkau'e iatona ssappoi pangkaukênnatoppegau

bawannge iatona nasanresi to madodonnge, naia bicarae, iana passaranngi assilangênna to mangkaga'e, naia rapangnge, iana passeajingngi tana masseajingnge, nakko marusa'ni Arumpone, adê'e temmassê'nitu arajanna Arummangkau'e, masolattoni tanae narekko têmmagettenni bicarae, masolanni ritu jemmatêbbe', narekko têmmagettenni rapannge, ianaritu Arumpone, mancaji assislangêng, gaga'enna ritu mancaji musu', musu'enna ritu mancaji assiunong, saba' makkuannanaro, Arumpone, narielorêng riatutui adê'e kuaetopa bicarae, ênrêngnge rapangnge, sibawa wari'e

\section{Nilai Pappaseng dalam Lontara' Latoa: Kajao Laliddong dengan Arumpone}

Nilai-nilai yang dimaksud di sini mengacu pada -sifat (hal-hal) yang penting atau berguna bagi kemanusiaan; sesuatu yang menyempurnakan manusia sesuai dengan hakikatnya.

Adapun nilai-nilai pappaseng dalam naskah Lontara' Latoa Percakapan antara Kajao Laliddong dengan Arumpone dibagi menjadi 4 (empat) bagian yaitu: 1) Nilai Kejujuran (Alempureng); 2) Nilai Kecendekiawan dan Kecerdasan (Amaccangêng); 3) Nilai Keteguhan (Agêttêngêng); dan 4) Nilai Kekeluargaan dan Kasih Sayang (Asseajingêng). Berikut pemaparannya:

a. Nilai Kejujuran (Alempureng)

Lontara' Latoa percakapan Kajao Laliddong dengan Arumpone memuat nilainilai kejujuran (alempureng). Hal ini tergambar jelas pada penjelasan Kajao Laliddong kepada Arumpone mengenai pappaseng berupa anjuran kepada seorang pemimpin untuk selalu jujur baik dalam perkataan maupun perbuatan. Kejujuran ini dapat diwujudkan dengan tindakan selalu mengatakan hal yang benar karena kejujuran adalah bukti kecendekiawan atau kecakapan seseorang atau pemimpin.

Selain itu kejujurandapat diwujudkan oleh tindakan seorang pemimpin yang selalu menyerukan kepada rakyatnya untuk menghormati dan tidak mengambil hak orang lain. Lambat laun kejujuran pemimpin akan membawa dampak yang baik bagi rakyat dan negaranya berupa kekayaan yang melimpah dan kemakmuran rakyatnya.

Berikut kutipan - kutipan dalam naskah lontara' Latoa percakapan Kajao Laliddong dengan Arumpone yang menunjukkan nilai kejujuran:

5) Makkêdai Kajao Laliddong, ia inanna waramparangnge Arumpone, 


\section{1 | JURNAL ILMU BUDAY}

Volume 8, Nomor 1, Juni 2020 têngngaluppange surona ppoada ada tongêng

12) Makkêdai Arumpone, apa appongênna accae, Kajao?

13) Makkêdai Kajao Laliddong, lempu'e Arumpone

14) Makkêdai Arumpone, aga sabbinna lêmpue, Kajao?

15) Makkêdai Kajao Laliddong, obbi'e Arumpone

16) Makkêdai Arumpone, agana ri obbirêng, Kajao? 17) Makkêdai Kajao Laliddong, iana ri obbirêng, Arumpone, makkêdae aja muala tanê - ttanêng tania tanê ttanêngmu, aja muala waramparang tania waramparammu, nataniato mana'mu, aja' to mupassu tedong tania tedommu, ênrêngnge annyarang tania annyarammu, aja to muala aju ripasanre' na tania iko pasanre'i, aja to muala aju riwêtta walia natani iko mpêttawaliwi

25) Makkêdai Kajao Laliddong, dua tanranna namaraja tanae, Arumpone. Seuani, malêmmpu'I na macca arummangkau'e

29) Makkêdai Kajao Laliddong, têllu tanranna nasawe ase, Arumpone. Seuani nakko malêmmpu'i Arummangkau'e,

b. Nilai Kecendekiawan dan Kecerdasan (Amaccangêng)

Jika menilik dua istilah di atas tidak terdapat perbedaan yang jauh hanya pada aspek proses saja. Cendekia berkaitan erat dengan kemampuan seseorang dalam beradaptasi sedangkan cerdas berkaitan erat dengan intelegensi atau kemampuan berpikir.

Adapun kutipan dalam naskah Lontara' Latoa percakapan Kajao Laliddong dengan Arumpone yang menunjukkan nilai kecendekiawan dan kecerdasan sebagai berikut:

5) Makkêdai Kajao Laliddong, ia inanna waramparangnge Arumpone, têttaroengngi natattêrê - têrê tau têmbe'na, têmmatinropi matanna arungnge ri êsso ri wênnie, nawanawai adecengênna tanana, natangngai olona munrinna gau'e, napogau'i; maduanna, maccapi ppinru' ada arung mangkau'e; matêllunna, maccapi dduppai ada arung mangkau'e; maêppa'na, têngngaluppange surona ppoada ada tongêng Makkêdai Arumpone, kega riasêng macca ppinru' ada, Kajao?

6) Makkêdai Kajao Laliddong, ianaritu Arumpone, macca ppinru’ ada tau têssalae ri pangngadêrrêngnge Makkêdai Arumpone, kegana riaseng macca dduppai ada, Kajao? Makkêdai Kajao Laliddong, ianaritu Arumpone, riaseng macca dduppai ada, tau têssalae ri rapannge

7) Makkêdai Arumpone, kegana riaseng tau tengngalupang surona ri ada tongêngnge, Kajao?

8) Makkêdai Kajao Laliddong, ianaritu Arumpone, riaseng tau tengngalupang surona ri ada tongêngnge, tau têttatakkalupae ri bicarae

9) Makkêdai Arumpone, apa appongênna accae, Kajao?

13) Makkêdai Kajao Laliddong, lempu'e Arumpone

18) Makkêdai Arumpone, aga sabbinna accae, Kajao?

19) Makkêdai Kajao Laliddong, gau'e sabbinna accae, arumpone

25) Makkêdai Kajao Laliddong, dua tanranna namaraja tanae, Arumpone. Seuani, malêmmpu'i na macca arummangkau'e

c. Nilai Keteguhan (Agêttêngêng)

Dalam hal ini pengertian yang sepadan denga nilai keteguhan dalam lontara' Latoa percakapan Kajao Laliddong dengan Arumpone kuat berpegang (pada adat, janji, perkataan). Hal ini dapat ditemukan pada kutipan dalam naskah Lontara' Latoa percakapan Kajao Laliddong dengan Arumpone sebagai berikut:

7) Makkêdai Kajao Laliddong, ianaritu Arumpone, macca ppinru' ada tau têssalae ri pangngadêrrêngnge

30) Makkêdatopi Kajao Laliddong, iaritu adê'e, Arumpone, ppeassêriwi arajanna 


\section{2 | JURNAL ILMU BUDAY}

Volume 8, Nomor 1, Juni 2020
Arummangkau'e iatona ssappoi pangkaukênnatoppegau bawannge iatona nasanresi to madodonnge, naia bicarae, iana passaranngi assilangênna to mangkaga'e, naia rapangnge, iana passeajingngi tana masseajingnge, nakko marusa'ni Arumpone, ade'e temmassê'nitu arajanna Arummangkau'e, masolattoni tanae narekko têmmagettenni bicarae, masolanni ritu jemmatêbbe', narekko têmmagettenni rapannge, ianaritu Arumpone, mancaji assisalangêng, gaga'enna ritu mancaji musu', musu'enna ritu mancaji assiunong, saba' makkuannanaro, Arumpone, narielorêng riatutui adê'e kuaetopa bicarae, ênrêngnge rapangnge, sibawa wari'e

d. Nilai Kekeluargaan dan Kasih Sayang (Asseajingêng)

Nilai kekeluargaan dan kasih sayang tidak hanya terwujud dalam lingkup keluarga saja yaitu antara orang tua dengan anak, saudara atau kerabat dekat. Namun, nilai kekeluargaan dan kasih sayang dapat juga diwujudkan dalam lingkup yang lebih besar dan luas yaitu dalam lingkup negara. Hal ini dapat tergambar dari hubungan yang baik antara pemimpin dengan rakyatnya. Hubungan saling mengasihi yang akan mewujudkan rasa saling peduli dan saling mendukung satu sama lain sehingga terwujudlah negara yang aman, tentram, dan damai.

Kutipan dalam naskah lontara' Latoa percakapan Kajao Laliddong dengan Arumpone yang menunjukkan nilai kekeluargaan dan kasih sayang sebagai berikut:

5) Makkêdai Kajao Laliddong, ia inanna waramparangnge Arumpone, têttaroengngi natattêrê - têrê tau têmbe'na, têmmatinropi matanna arungnge ri êsso ri wênnie, nawa - nawai adecengênna tanana, ...............

23) Makkêdai Kajao Laliddong, iana tanra cinna matena tana marajae, Arumpone, tênnamaseiwi atanna
30) Makkêdatopi Kajao Laliddong, iaritu adê'e, Arumpone,.............. iatona nasanresi to madodonnge, naia bicarae, iana passaranngi assilangênna to mangkaga'e, naia rapangnge, iana passeajingngi tana masseajingnge, ............

\section{KESIMPULAN}

Pesan atau pappaseng yang terdapat dalam Lontara' Latoa percakapan antara Kajao Laliddong dengan Arumpone mengenai hal-hal yang berkenaan dengan tata cara seorang pemimpin / raja memperlakukan rakyatnya begitu pun sebaliknya yaitu tentang ciri pemimpin harus memiliki karakter yang jujur dan cakap dalam perkataan maupun perbuatannya. Karakter seorang pemimpin inilah yang akan menentukan jaya atau hancurnya suatu negara / kerajaan.

Segala hal yang mengatur tentang hal tersebut termaktub dengan apik dalam sebuah sistem norma yang berlaku pada masyarakat Bugis yang disebut pangngadêrêng mencakup 4 unsur penting yaitu adê', bicara, rapang, dan wari.

Lontara' Latoa percakapan antara Kajao Laliddong dengan Arumpone memuat makna dan nilai-nilai luhur yang harus dijaga dan dilestarikan. Makna-maknanya meliputi ciri pemimpin yang baik, tanda kehancuran dan kejayaan sebuah negara, dan sistem pemerintahan yang berpedoman pada sistem norma. Nilai-nilai yang terkandung dalam Lontara' Latoa percakapan antara Kajao Laliddong dengan Arumpone mencakup nilai-nilai kejujuran (alêmpurêng), nilai kecendekiawan (amaccangêng), keteguhan (agêttêngêng), serat nilai kekeluargaan dan kasih sajang (assiajingêng). Kesemuanya itu jika diterapkan dalam kehidupan masyarakat akan menciptakan kedamaian dan kesejahteraan, bukan saja dalam lingkup suku, bahkan negara ataupun dunia. 


\section{3 | JURNAL ILMU BUDAY A}

Volume 8, Nomor 1, Juni 2020

\section{DAFTAR PUSTAKA}

Arifin, Zaenal. 2003. "Hermeneutika Fenomenologis Paul Ricoeur", dalam Nafisul "Atho dan Arif Fahruddin (ed.), Hermeneutika Transendental; Dari Konfigurasi Filosofis Menuju Praksis Islamic Studies, Yogyakarta: IRCiSoD. .

Chaer, Abdul. 2007. Kajian Bahasa. Jakarta: Rineka Cipta.

Darmadi, Hamid. 2009. Dasar Konsep Pendidikan Moral. Bandung: Alfabeta.

Eagleton, Terry. 2006. Teori Sastra: Sebuah Pengantar Komprehensif . Harfiah, Yogyakarta: Jalasutra.

Faiz, Fakhruddin. 2002. Hermeneutika alQur'an. Yogyakarta: Qolam, Cet.III. Hadi W.M., Abdul. 2004. Hermeneutika, Estetika, dan Religiusitas. Yogyakarta: Mahatari.

Hamid, Abu dkk. 2007. Sejarah Bone. Bone: Dinas Kebudayaan dan Pariwisata Kabupaten Bone

Hasyim, Muhammad, Kuswarini, Prasuri, Masdiana. 2019. Toraja Coffee As Tourism Identity: Perception of Foreign Tourists. Proceedings. First International Conference on Culture, Education, Linguistics and Literature (CELL), 5-6 August, Purwokerto, Central Java, Indonesia

Hidayati, Siti Nur. 2013. "Konsep Etika Peserta Didik Berdasarkan Pemikiran Syaihk Al Zarnuji dalam Kitab Ta'lim Muta'alim dan Implikasi Bagi Siswa Madrasah Ibtidaiyah" Skripsi. Jakarta: Fakultas PAI - UIN Yogyakarta.

Iskandar. 2016. "Bentuk, Makna, dan Fungsi Pappaseng dalam kehidupan Masyarakat Bugis di Kabupaten Bombana". Jurnal Bastra (Bahasa dan Sastra) Volume 1 No. 2. Kendari: Universitas Haluoleo.

Mattalitti, M. Arief, dkk. 1985. Pappaseng Tomatoa. Ujung Pandang: Balai Penelitian Bahasa Ujung Pandang.

Mattulada. 1995. Latoa: Suatu Lukisan Analitis Terhadap Antroplogi Politik Orang Bugis. Makassar: Hasanuddin University Press.

Nonci, Pesan - Pesan Tradisional (pappaseng toriolo): Makassar: CV.Aksara,
Karya Mandiri Jaya

Palmer, Richard E. 2005. Interpratation Theory in Schleirmacher, Dilthey, Heidegger, and Gadamer, terj. Mansur Hery \& Damanhuri M, Hermeneutika, Teori Baru Mengenai Interpretasi, Yogyakarta: Pustaka Pelajar.

Palmer, Richard E. 2005 Hermeneutika: Teori Baru mengenai Interpretasi. Yogyakarta: Pustaka Pelajar.

Pelras, Cristian. 2006. Manusia Bugis. Jakarta: Nalar bekerja sama Forum Jakarta - Paris EFEO.

Rahardjo, Mudjia. 2007. Hermeneutika Gadamerian: Kuasa Bahasa dalam Wacana Politik Gus Dur Malang: Universitas Islam Negara - Malang Press.

Rahman, Abd. 2014. "Pesan-pesan Dakwah yang Terkandung dalam Pappasang Lontara' Makassar" Skripsi. Makassar: Fakultas dakwah dan Komunikasi UIN Makassar.

Rasyid, Darwas, 1994. Laporan Penelitian Sejarah dan Nilai Tradisional Sulawesi Selatan (Latenritatta Aru' Palakka dalam Konteks Sejarah). Ujung Pandang : Departemen Pendidikan dan Kebudayaan Sulawesi Selatan.

Ricoeur, Paul. 2014. Teori Interpretasi Membelah Makna dalam Anatoni Teks. Jogjakarta: IRCiSoD 